\title{
Correlation between ECG changes and early left ventricular remodeling in preadolescent footballers
}

\author{
M Zdravkovic ${ }^{1}$, B Milovanovic ${ }^{1}$, S Hinic ${ }^{1}$, I Soldatovic ${ }^{2}$, T Durmic ${ }^{3}$, G Koracevic ${ }^{4}$, \\ S Prijic ${ }^{5}$, O Markovic ${ }^{1}$, B Filipovic ${ }^{1}$, D Lovic ${ }^{6}$ \\ ${ }^{1}$ Faculty of Medicine, University Hospital Medical Center Bezanijska Kosa, University of Belgrade, Belgrade, Serbia \\ ${ }^{2}$ Faculty of Medicine, Institute for Medical Statistics, University of Belgrade, Belgrade, Serbia \\ ${ }^{3}$ Faculty of Medicine, Institute of Forensic Medicine, University of Belgrade, Belgrade, Serbia \\ ${ }^{4}$ Faculty of Medicine, Clinic for Cardiology, University of Nis, Nis, Serbia \\ ${ }^{5}$ Department of Cardiology, Faculty of Medicine, Institute for Child and Mother Care "Vukan Cupic", University of \\ Belgrade, Belgrade, Serbia \\ ${ }^{6}$ Clinic for Internal Diseases "InterMedica", Nis, Serbia
}

Received: July 25, 2016

Accepted: February 9, 2017

The aim of this study was to assess the early electrocardiogram (ECG) changes induced by physical training in preadolescent elite footballers. This study included 94 preadolescent highly trained male footballers (FG) competing in Serbian Football League (minimum of 7 training hours/week) and 47 age-matched healthy male controls (less than 2 training hours/week) (CG). They were screened by ECG and echocardiography at a tertiary referral cardio center. Sokolow-Lyon index was used as a voltage electrocardiographic criterion for left ventricular hypertrophy diagnosis. Characteristic ECG intervals and voltage were compared and reference range was given for preadolescent footballers. Highly significant differences between FG and CG were registered in all ECG parameters: P-wave voltage $(p<0.001)$, S-wave (V1 or V2 lead) voltage $(p<0.001)$, R-wave (V5 and V6 lead) voltage $(p<0.001)$, ECG sum of $\mathrm{S} \mathrm{V}_{1-2}+\mathrm{R} \mathrm{V}_{5-6}(p<0.001)$, T-wave voltage $(p<0.001)$, QRS complex duration $(p<0.001)$, T-wave duration $(p<0.001)$, QTc interval duration $(p<0.001)$, and $\mathrm{R} / \mathrm{T}$ ratio $(p<0.001)$. No differences were found in PQ interval duration between these two groups $(p>0.05)$. During 6-year follow-up period, there was no adverse cardiac event in these footballers. None of them expressed pathological ECG changes. Benign ECG changes are presented in the early stage of athlete's heart remodeling, but they are not related to pathological ECG changes and they should be regarded as ECG pattern of LV remodeling.

Keywords: athletes, cardiology, electrocardiography, heart, footballers

\section{Introduction}

Electrocardiogram (ECG) and echocardiographic changes in athletes are common and usually reflect structural and electrical remodeling of the heart as an adaptation to regular physical training and hemodynamic changes that alter the loading conditions of the heart, causing the athlete's heart syndrome (2). However, the level and duration of training or competition, aerobic capacity, and type of sports activity play an important role in the extent of physiological changes of the athlete's heart syndrome $(1,19)$.

Most of the health problems associated with increased risk of sudden cardiac death (SCD), such as cardiomyopathies and primary rhythm disorders due to the electrical

Corresponding author: Dr. Marija Zdravkovic, MD, PhD, FESC, FESH

Faculty of Medicine, University Hospital Medical Center Bezanijska Kosa, University of Belgrade

Bezanijska kosa bb, 11000 Belgrade, Serbia

Phone: +381 648114258; Fax: +381 112606520; E-mail: sekcija.kardioloska@gmail.com 
damages, are suspected by abnormal findings present on an ECG. ECG interpretation in athletes requires a very detailed analysis to properly define physiological changes related to athlete's heart from findings suggestive of an underlying cardiac disease $(3,31)$. The main goal of the ECG evaluation in athletes is to describe ECG as: (a) "normal" - no further evaluation needed or (b) "abnormal" - further evaluation needed. Abnormal findings are unrelated to regular training and also found in underlying pathological cardiac conditions. These include findings suggestive of cardiomyopathy, such as T-wave inversion, ST depression, pathological Q waves, left axis deviation and conduction delays, and findings suggestive or diagnostic of primary electrical diseases, such as long QT syndrome and Wolff-Parkinson-White syndrome.

Several recommendations elucidated pathological ECG signs in athletes $(5,6,11$, $12,15)$; however, data regarding preadolescent athletes are quite limited $(9,13,30)$. Several studies have concluded that there is early left ventricular remodeling in preadolescent football players, but data regarding early ECG changes are missing $(9,22,33)$.

In the following study, the tested hypothesis was: there are differences in ECG parameters between two compared groups in early preadolescent period, elite football players, and age-matched sedentary controls induced by specific athlete's heart syndrome. The second aim of this study was to investigate QTc interval correlation with echocardiographic parameters in elite preadolescent football players. The third aim of this study is to address the relative lack of data in the literature regarding normal values of ECG parameters in preadolescent population of football players.

\section{Materials and Methods}

\section{Study design}

A group of 94 Caucasian elite male football players aged 12.85 (0.84), all being members of the National Football Premier League clubs (age range: 12-14 years), were included. The control group consisted of 47 healthy male age-matched sedentary controls, who were not exercising regularly (sport training for not more than $2 \mathrm{~h} /$ week). None of the participants had any symptoms attributable to cardiovascular disease. No subject was taking any form of prescribed drug treatment. There are no pathological findings on physical examination of all participants. They all were normotensives and nonsmokers. All athletes had been regularly engaged in active training for at least 3 years and were in their active training season. They had, on average, $9 \mathrm{~h}$ of weekly training which included: 5-h specific football training, 2-h anaerobic dynamic training, 1-h strength training, and 1-h aerobic endurance activities. The sample size was calculated to have a power more than $80 \%$ to detect a difference at $p<0.05$.

Echocardiographic evaluation was performed by the same experienced cardiologist who was blind to the subject's training group on every occasion using Acuson Sequoia computed sonography platform with a probe frequency $3.5 \mathrm{MHz}$ vector array format transducer following the recommendations of the American Society of Echocardiography (ASE) (11). The images were obtained in the parasternal long and short axis, in left lateral position, and also in the four-chamber view and then analyzed off-line. Both M-mode and crosssectional studies were performed. The measurements of the left atrium (LA), aortic root (AO), left ventricular end-diastolic dimension (LVED), left ventricular end-systolic dimension (LVES), left ventricular posterior wall diastolic dimension (PWd), interventricular septal end-diastolic dimension (IVSd) were done in the parasternal long axis view, by the average of three consecutive cardiac cycles with concomitant ECG and the average was calculated. 
Left ventricular ejection fraction (EF) was calculated by Simpson's rule. Left ventricular mass (LV mass) was calculated using the method described by Devereux and Reichek (8).

$$
\mathrm{LVM}=1.04 \times[(\text { LVED }+ \text { PWd }+ \text { IVSd }) 3-\text { LVED3 }]-13.6 \mathrm{~g} .
$$

Left ventricular mass index (LVMI) was calculated by standard dividing LV mass by body surface area (BSA) (8).

All heart valves were assessed by standard technique to exclude significant valvular and subvalvular obstruction and regurgitation. Valve regurgitation severity was evaluated in accordance with the recommendations of the ASE Guidelines (11).

As LVM is known to vary with body size and composition, normalization of LV dimensions according to body size is very important in comparisons between different subject groups. In children and adolescents, increased cardiac size is directly proportional to the increase in body height; therefore, these adjustments according to body size were done for comparison of cardiac dimensions: LV mass findings were adjusted to BSA ${ }^{1.5}$ and LVM was additionally adjusted to height ${ }^{2.7}(7)$.

Standard 12-lead ECG was recorded using a Nihon Kohden recorder with a paper speed of $25 \mathrm{~mm} / \mathrm{s}$ and amplification of $0.1 \mathrm{mV} / \mathrm{mm}$. The QT interval was measured automatically in all leads from the onset of QRS complex to the end of $\mathrm{T}$ wave, defined as the intersection of isoelectric line and the tangent of the maximal downward limb of the T wave (23). The QTc values were derived using Bazett's formula, which has been most widely used in all large studies evaluating patients with LQTS (16). The Bazett's correction is commonly used in QTc interval investigations and involves dividing the uncorrected QT (in seconds) by the square root of the RR interval (in seconds). The limitations of this method are over-correction at faster heart rates (lower RR intervals) and under-correction at slower heart rates (higher RR intervals).

We used Sokolow-Lyon index electrocardiographic criteria for left ventricular hypertrophy ( $\mathrm{LVH})$, defined when the voltage amplitude sum of $\mathrm{S} \mathrm{V}_{1-2}+\mathrm{R}_{5-6}$ at baseline was equal to or above $3.5 \mathrm{mV}$ (27).

All ECGs were analyzed independently by two independent cardiologists with a clinical and academic interest in ECGs, blinded to all clinical details of the subjects, using a millimeter ruler and calipers. Since this study involved minor athletes, their parents, after being informed about the possible investigation risks, gave the written informed consent. All of the procedures were approved by the Ethics Committee of the University of Belgrade School of Medicine, conducted in accordance with the World Medical Association Declaration of Helsinki.

\section{Statistical analysis}

Continuous data are expressed as mean (SD), with 5th and 95th percentile ranges to facilitate comparison with the data belonging to the controls. Statistical analysis was carried out using unpaired $t$-tests between groups. Statistical significance is stated as $p<0.05$.

\section{Results}

Selected physical characteristics of the football players and the controls are shown in Table I.

The football players had similar height as the control group, but significantly smaller weight and BSA. Heart rate was significantly lower in athletes then in control subjects. 
Table I. The characteristics of the 94 football players and 47 age-matched non-athletes (mean and SD)

\begin{tabular}{|c|c|c|c|}
\hline & Football players & Non-athletes & $p$ \\
\hline Age (years) & $12.85(0.84)$ & $12.85(0.86)$ & NS \\
\hline Height $(\mathrm{cm})$ & $159.36(10.65)$ & $162.71(13.09)$ & NS \\
\hline Weight $(\mathrm{kg})$ & $48.27(10.62)$ & $58.28(13.07)$ & $<0.001$ \\
\hline BSA $\left(\mathrm{m}^{2}\right)$ & $1.45(0.20)$ & $1.61(0.24)$ & $<0.001$ \\
\hline BMI $\left(\mathrm{kg} / \mathrm{m}^{2}\right)$ & $18.75(1.92)$ & $21.59(1.86)$ & $<0.001$ \\
\hline HR (bpm) & $83.49(14.50)$ & $88.8(5.19)$ & $<0.001$ \\
\hline $\begin{array}{l}\text { Systolic blood pressure } \\
(\mathrm{mmHg})\end{array}$ & $109.95(8.08)$ & $108.19(6.71)$ & NS \\
\hline $\begin{array}{l}\text { Diastolic blood pressure } \\
(\mathrm{mmHg})\end{array}$ & $65.74(7.89)$ & $60.75(5.80)$ & $<0.001$ \\
\hline
\end{tabular}

BSA: body surface area; BMI: body mass index; HR: heart rate; bpm: beats per minute; NS: non-significant.

Values of systolic blood pressure were similar in both groups, but diastolic blood pressure was higher in athletes, nevertheless normal.

Table II shows comparison of the ECG findings in 94 preadolescent football players and 47 age-matched non-athletes (mean and SD).

Although all examined ECG parameters were within normal values for study population, highly significant differences between preadolescent athletes and sedentary controls were registered in all ECG parameters: P-wave voltage $(p<0.001)$, S-wave (V1 or V2 lead) voltage $(p<0.001)$, R-wave (V5 and V6 lead) voltage $(p<0.001)$, ECG sum of S $\mathrm{V}_{1-2}+$ $\mathrm{R} \mathrm{V}_{5-6}(p<0.001)$, T-wave voltage $(p<0.001)$, QRS complex duration $(p<0.001)$, T-wave duration $(p<0.001)$, QTc interval duration $(p<0.001)$, and $\mathrm{R} / \mathrm{T}$ ratio $(p<0.001)$. Namely, all examined ECG parameters were higher in football players compared with control group. No differences were found in PQ interval duration between these two groups $(p>0.05)$.

All participants had normal values of QTc interval. Mean QTc interval in athletes in rest was significantly longer $419.89 \pm 13.07 \mathrm{~ms}$, compared with mean QTc in the control sedentary group: $399.78 \pm 13.27 \mathrm{~ms}(p<0.001)$. The mean and SD of the QTc values in football players as well as in non-athletes are shown in Table II, together with correlations of these parameters to echocardiographic measurements.

QTc interval duration in athletes had not very strong, but indeed positive correlation to LA dilatation, LV end-systolic and end-diastolic dimensions, LVMI, and LVM/BSA ${ }^{1.5}$ and $\mathrm{LVM} / \mathrm{h}^{2.7}$ indices. There was no correlation between QTc interval duration and LVM as well as LV wall thickness.

Keeping the third aim of this study in mind addressing the relative lack of data in the literature regarding normal values of ECG parameters in preadolescent population of football players, derived reference values of ECG parameters for preadolescent football players are presented in Table III.

Table IV shows comparison of the resting echocardiographic findings in 94 football players and 47 age-matched non-athletes and correlation between QTc interval duration and echocardiographic parameters in adolescent young football players. 
Table II. Comparison of the ECG findings in 94 preadolescent football players and 47 age-matched non-athletes (mean and SD)

\begin{tabular}{|l|c|c|c|c|}
\hline & $\begin{array}{c}\text { Football } \\
\text { players }\end{array}$ & Non-athletes & $\boldsymbol{t}$ & $\boldsymbol{p}$ \\
\hline HR (bpm) & $83.49(14.50)$ & $88.8(5.19)$ & -19.14 & $<0.001^{* *}$ \\
\hline P wave (mm) & $1.96(0.16)$ & $1.34(0.46)$ & 11.81 & $<0.001^{* *}$ \\
\hline S wave (mm) (V1 or V2 lead) & $12.11(2.61)$ & $10.66(2.09)$ & 3.31 & $<0.001^{* *}$ \\
\hline R wave (mm) (R5 or R6) & $17.21(2.35)$ & $15.28(2.24)$ & 4.69 & $<0.001^{* *}$ \\
\hline S V 1-2 $^{*} \mathrm{R} \mathrm{V_{5-6 } { } ^ { a }}$ & $29.42(3.91)$ & $24.89(3.59)$ & 5.19 & $<0.001^{* *}$ \\
\hline T wave (mm) & $8.10(2.33)$ & $4.15(1.00)$ & 11.107 & $<0.001^{* *}$ \\
\hline R wave (aVL) & 3.92 & 3.06 & 6.34 & $<0.001^{* *}$ \\
\hline S wave (V3) & 9.65 & 8.21 & 4.08 & $<0.001^{* *}$ \\
\hline PQ interval duration & $174.02(3.57)$ & $162.84(1.56)$ & -2.06 & $<0.05$ \\
\hline QRS complex duration & $82.44(1.30)$ & $76.01(0.1)$ & 3.19 & $<0.001^{* *}$ \\
\hline T-wave duration & $205.14(2.62)$ & $173.82(2.03)$ & -7.80 & $<0.001^{* *}$ \\
\hline QTc interval duration & $419.89(13.07)$ & $399.78(13.27)$ & 8.57 & $<0.001^{* *}$ \\
\hline R/T & $2.29(0.72)$ & $3.89(1.06)$ & -10.50 & $<0.001^{* * *}$ \\
\hline
\end{tabular}

HR: heart rate; bpm: beats per minute.

${ }^{a}$ Sokolow-Lyon index: electrocardiographic criteria for $\mathrm{LVH}$, defined as voltage amplitude sum of $\mathrm{S} \mathrm{V} \mathrm{V}_{1-2}+\mathrm{R} \mathrm{V}_{5-6}$ at baseline equal to or above $3.5 \mathrm{mV}$.

$* * p<0.001$ compared with controls

There was a statistically significant difference in AO, LA, left ventricular diameters, as well as in LVMI and QTc interval duration $(p<0.01)$. Namely, all these values, although still in normal reference range, were significantly higher in athletes compared with the control group. Also, there was a statistically significant correlation between all these parameters and QTc interval duration $(p<0.01)$.

Concerning the examined echocardiographic dimensions, although they differ from data given in the literature, they fit in normal values in accordance with standard relevant guidelines for the population examined (7).

\section{Discussion}

The data indicate that although all ECG parameters were within the normal range for the population studied, they were significantly different in preadolescent football players compared with age-matched sedentary controls. None of the clearly pathological ECG signs was detected either in preadolescent football players or in sedentary controls. It was not surprising that the resting heart rates of the athletes were faster than the typically reported heart rate in the previous studies, as this was the unique age group of very young athletes. 
Table III. The reference values of ECG parameters for readolescent football players

\begin{tabular}{|l|c|c|}
\hline & \multicolumn{2}{|c|}{ Reference values } \\
\hline Electrocardiographic parameters & Football players & Non-athletes \\
\hline HR (bpm) & $65-82$ & $82-99$ \\
\hline P-wave voltage (mV) & $1.5-2.0$ & $0.5-2.0$ \\
\hline S-wave voltage (V1 or V2) (mV) & $8.0-16.2$ & $8.0-14.0$ \\
\hline R-wave voltage (R5 or R6) (mV) & $14.0-22.0$ & $11.0-19.0$ \\
\hline Sokolow-Lyon index (mV) & $24.0-36.2$ & $19.4-32.0$ \\
\hline T-wave voltage (mV) & $5.0-12.0$ & $3.0-6.0$ \\
\hline PQ interval duration (ms) & $140-220$ & $120-200$ \\
\hline QRS complex duration (ms) & $60-110$ & $60-80$ \\
\hline T-wave duration (ms) & $160-220$ & $160-240$ \\
\hline QTc interval duration & $397.5-440.0$ & $380.0-420.0$ \\
\hline R/T & $1.42-3.62$ & $2.08-5.67$ \\
\hline
\end{tabular}

HR-heart rate; bpm: beats per minute.

Sokolow-Lyon index: electrocardiographic criteria for $\mathrm{LVH}$, defined as voltage amplitude sum of $\mathrm{S} \mathrm{V}_{1-2}+\mathrm{R} \mathrm{V}_{5-6}$ at baseline equal to or above $3.5 \mathrm{mV}$

Normal ECGs in adult include common, training-related findings in athletes, such as high QRS amplitude meeting voltage criteria for LVH, early repolarization, sinus bradycardia, sinus arrhythmia, and first-degree atrioventricular block $(5,20,29,31)$. None of these findings were registered in our group due to the very young age of the investigated athletes. Additionally, Sokolow-Lyon index, as the voltage criteria for LVH used in this study, of both examined groups fits in the normal values of children this age (24). Namely, it is well known that the pediatric ECG interpretation is heavily dependent upon patient age. This fact is of utmost importance particularly during proper LVH interpretation. Although football players have increased almost all examined ECG parameters compared with control group, these values are still in the normal range. Keeping the above-mentioned facts in mind, may be the most important fact is to correlate clinical parameters, along with the developmental ECG changes and sports history in this particular sensitive population.

Also, the echocardiographic measurements observed in this study were lower than in the large-scale surveillance studies of preadolescent athletes. This can be explained by the intensity of training in athletes, which was a selected, predominantly moderate, training workload $(14,19,21)$.

The QT interval represents the time necessary to achieve ventricular activation until the termination of repolarization. Its length depends both on ventricular conduction velocity and repolarization.

According to the literature, QT interval prolongation is widely associated with increased ventricular mass and it correlates with the extent of hypertrophy $(10,30)$. On the other hand, in athletes with physiological left ventricular remodeling the QT interval is normal and along with the QTc interval it responds normally to exercise. 
Table IV. Comparison of the resting echocardiographic findings in 94 football players and 47 age-matched non-athletes and correlation between QTc interval duration and echocardiographic parameters in adolescent young football players (mean and SD)

\begin{tabular}{|c|c|c|c|c|c|}
\hline & $\begin{array}{c}\text { Football } \\
\text { players }\end{array}$ & Non-athletes & $p$ & $\begin{array}{c}\text { QTe } \\
\text { correlation }\end{array}$ & $\S$ \\
\hline Ao $\left(\mathrm{mm}\right.$ per $\left.\mathrm{BSA}^{0.5}\right)$ & $21.87(2.08)$ & $15.65(1.36)$ & $<0.01$ & 0.478 & $<0.05$ \\
\hline LA (mm per $\left.\mathrm{BSA}^{0.5}\right)$ & $23.18(2.07)$ & $20.15(2.87)$ & $<0.01$ & 0.221 & $<0.01$ \\
\hline LVED (mm per $\left.\mathrm{BSA}^{0.5}\right)$ & $38.72(2.53)$ & $35.68(2.54)$ & $<0.01$ & 0.351 & $<0.01$ \\
\hline LVES (mm per BSA ${ }^{0.5}$ ) & $25.83(2.58)$ & $20.75(2.30)$ & $<0.01$ & 0.374 & $<0.01$ \\
\hline IVSd (mm per BSA $\left.{ }^{0.5}\right)$ & $7.08(0.70)$ & $6.53(0.81)$ & NS & 0.089 & NS \\
\hline PWd (mm per $\mathrm{BSA}^{0.5}$ ) & $6.82(0.73)$ & $6.46(0.80)$ & NS & -0.045 & NS \\
\hline LVM (g) & $160.14(33.14)$ & $149.59(34.01)$ & NS & 0.096 & NS \\
\hline LVMI (g per BSA) & $109.79(15.04)$ & $92.84(18.29)$ & $<0.01$ & 0.235 & $<0.01$ \\
\hline LVM/BSA ${ }^{1.5}\left(\mathrm{~g}_{\text {per }} \mathrm{BSA}^{1.5}\right)$ & $91.55(13.86)$ & $73.73(16.54)$ & $<0.01$ & 0.339 & $<0.01$ \\
\hline $\mathrm{LVM} / \mathrm{h}^{2.7}\left(\mathrm{~g}\right.$ per BSA $\left.{ }^{1.5}\right)$ & $45.78(9.47)$ & $40.65(9.29)$ & $<0.01$ & 0.298 & $<0.01$ \\
\hline QTc (ms) & $419.89(13.27)$ & $399.78(13.07)$ & $<0.01$ & & $<0.01$ \\
\hline
\end{tabular}

BSA: body surface area; BMI: body mass index; HR: heart rate; Ao: aortic root diameter; LA: left atrium; LVED: left ventricular end-diastolic dimension; LVES: left ventricular end-systolic dimension; IVSd: interventricular septal enddiastolic dimension; PWd: left ventricular posterior wall diastolic dimension; LVM: left ventricular mass; LVMI: left ventricular mass index; $\mathrm{h}$ : height; $p$ : $p$ value from comparison of the resting echocardiographic findings in 94 football players and 47 age-matched non-athletes; $§$ : correlation of echocardiographic parameters and QTc interval duration; NS: non-significant

At the same time, increased left ventricular wall thickness is not common in preadolescent period and consequently a QTc prolongation is less likely to be expected (18).

However, our data indicate there is no correlation between QTc interval duration and LV wall thickness, analysis of specific LV mass indices revealed that correlation between these indices and QTc prolongation could be the explanation for the QTc prolongation $(17,33)$. Furthermore, QTc prolongation could be the early ECG marker of physiological LV remodeling in young preadolescent football players, without any other standard ECG and echocardiographic signs of early LV hypertrophy. This fact could be explained by a different pattern of left ventricular remodeling in preadolescent period, where LV wall thickness increase cannot usually be seen and the predominant characteristic is left ventricular dilatation. In our opinion, QTc prolongation in athletes is related to the early cardiac remodeling and can be seen even after a short period of training; nevertheless, recommended normal values of QTc interval in young preadolescent football players should be expected $(25,26,28)$.

\section{Limitations}

This study is limited to Serbian Caucasian preadolescent football players and differences with other races can occur $(4,25,32)$. Although further study is necessary, we expect athletes with different sports to have similar findings $(26,33,34)$. 


\section{Conclusion}

In summary, this study has shown that there are highly significant differences in ECG interval between preadolescent football players and age-matched controls. A prolongation of QTc interval in highly trained preadolescent football players compared with the QTc interval in preadolescents with sedentary life style and correlates with specific LV mass indices. However, this prolongation is still within recommended values. QTc prolongation could be the early ECG marker of physiological LV remodeling in young preadolescent football players, without any other standard ECG and echocardiographic signs of early LV hypertrophy.

\section{Acknowledgements}

The results of this study are part of the PhD thesis of Marija Zdravkovic and the project of the Ministry of Science of Republic of Serbia III 41022. There were no grants, no external financial or technical support, or other assistance during the evaluation of this study.

\section{Conflict of interest}

The authors declare no conflict of interest.

\section{REFERENCES}

1. Asif IM, Drezner JA: Detecting occult cardiac disease in athletes: history that makes a difference. Br. J. Sports Med. 47, 669 (2013)

2. Baggish AL, Wood MJ: Athlete's heart and cardiovascular care of the athlete: scientific and clinical update. Circulation 123, 2723-2735 (2011)

3. Basavarajaiah S, Wilson M, Whyte G, Shah A, McKenna W, Sharma S: Prevalence of hypertrophic cardiomyopathy in highly trained athletes: relevance to pre-participation screening. J. Am. Coll. Cardiol. 51, 1033-1039 (2008)

4. Chandra N, Papadakis M, Sharma S: Cardiac adaptation in athletes of black ethnicity: differentiating pathology from physiology. Heart 98, 1194-1200 (2012)

5. Corrado D, Biffi A, Basso C, Pelliccia A, Thiene G: 12-lead ECG in the athlete: physiological versus pathological abnormalities. Br. J. Sports Med. 43, 669-676 (2009)

6. Corrado D, Pelliccia A, Heidbuchel H, Sharma S, Link M, Basso C, Biffi A, Buja G, Delise P, Gussac I, Anastasakis A, Borjesson M, Bjørnstad HH, Carrè F, Deligiannis A, Dugmore D, Fagard R, Hoogsteen J, Mellwig KP, Panhuyzen-Goedkoop N, Solberg E, Vanhees L, Drezner J, Estes NA 3rd, Iliceto S, Maron BJ, Peidro R, Schwartz PJ, Stein R, Thiene G, Zeppilli P, McKenna WJ, Section of Sports Cardiology, European Association of Cardiovascular Prevention and Rehabilitation: Recommendations for interpretation of 12-lead electrocardiogram in the athlete. Eur. Heart J. 31, 243-259 (2010)

7. De Simone G, Daniels SR, Devereux RB, Meyer RA, Roman MJ, de Divitiis O, Alderman MH: Left ventricular mass and body size in normotensive children and adults: assessment of allometric relations and impact of overweight. J. Am. Coll. Cardiol. 20, 1251-1260 (1992)

8. Devereux RB, Reichek N: Echocardiographic determination of left ventricular mass in man. Circulation 55, 613-618 (1977)

9. Drezner JA, Ackerman MJ, Cannon BC, Corrado D, Heidbuchel H, Prutkin JM, Salerno JC, Anderson J, Ashley E, Asplund CA, Baggish AL, Börjesson M, DiFiori JP, Fischbach P, Froelicher V, Harmon KG, Marek J, Owens DS, Paul S, Pelliccia A, Schmied CM, Sharma S, Stein R, Vetter VL, Wilson MG: Abnormal electrocardiographic findings in athletes: recognising changes suggestive of primary electrical disease. Br. J. Sports Med. 47, 153-167 (2013)

10. La Gerche A, Macisaac AI, Prior DL: Should pre-participation cardiovascular screening for competitive athletes be introduced in Australia? A timely debate in a sport-loving nation. Heart Lung Circ. 20, 629-633 (2011) 
11. Lang RM, Bierig M, Devereux RB, Flachskampf FA, Foster E, Pellikka PA, Picard MH, Roman MJ, Seward J, Shanewise JS, Solomon SD, Spencer KT, Sutton MS, Stewart WJ: Recommendations for chamber quantification: a report from the American Society of Echocardiography's Guidelines and Standards Committee and the Chamber Quantification Writing Group, developed in conjunction with the European Association of Echocardiography, a branch of the European Society of Cardiology. J. Am. Soc. Echocardiogr. 18, 1440-1463 (2005)

12. Langdeau JB, Blier L, Turcotte H, O'Hara G, Boulet LP: Electrocardiographic findings in athletes: the prevalence of left ventricular hypertrophy and conduction defects. Can. J. Cardiol. 17, 655-659 (2001)

13. Makarov LM: Sudden death in young athletes. Kardiologiia 50, 78-83 (2010)

14. Manolas VM, Pavlik G, Bánhegyi A, Faludi J, Sidó Z, Olexó ZS: Echocardiographic changes in the development of the athlete's heart in 9 to 20-year-old male subjects. Acta Physiol. Hung. 88, 259-270 (2001)

15. Maron BJ, Chaitman BR, Ackerman MJ, Bayés de Luna A, Corrado D, Crosson JE, Deal BJ, Driscoll DJ, Estes NA 3rd, Araújo CG, Liang DH, Mitten MJ, Myerburg RJ, Pelliccia A, Thompson PD, Towbin JA, Van Camp SP, Working Groups of the American Heart Association Committee on Exercise, Cardiac Rehabilitation, and Prevention, Councils on Clinical Cardiology and Cardiovascular Disease in the Young: Recommendations for physical activity and recreational sports participation for young patients with genetic cardiovascular diseases. Circulation 109, 2807-2816 (2004)

16. Napolitano C, Bloise R, Priori SG: Long QT syndrome and short QT syndrome: how to make correct diagnosis and what about eligibility for sports activity. J. Cardiovasc. Med. (Hagerstown) 7, 250-256 (2006)

17. Palatini P, Maraglino G, Mos L, Munari L, Ronsisvalle G, Calzavara A, Lusiani L, Libardoni M, Pessina AC, Dal Palù C: Effect of endurance training on Q-T interval and cardiac electrical stability in boys aged 10 to 14 . Ventricular arrhythmias in trained boys. Cardiology 74, 400-407 (1987)

18. Patel DR, Luckstead EF Sr: Update on cardiovascular screening: can we prevent sudden cardiac death in adolescent athletes? Adolesc. Med. State Art Rev. 24, 225-241 (2013)

19. Pavlik G, Major ZS, Csajági E, Jeserich M, Kneffel ZS: The athlete's heart. Part II. Influencing factors on the athlete's heart: types of sports and age. Acta Physiol. Hung. 100, 1-27 (2013)

20. Pavlik G, Major ZS, Varga-Pintér B, Jeserich M, Kneffel ZS: The athlete's heart Part I (Review). Acta Physiol. Hung. 97, 337-353 (2010)

21. Pavlik G, Olexó ZS, Frenkl R: Echocardiographic estimates related to various body size measures in athletes. Acta Physiol. Hung. 84, 171-181 (1996)

22. Pelliccia A, Maron BJ, Spataro A, Proschan MA, Spirito P: The upper limit of physiologic cardiac hypertrophy in highly trained elite athletes. N. Engl. J. Med. 324, 295-301 (1991)

23. Rautaharju PM, Surawicz B, Gettes LS, Bailey JJ, Childers R, Deal BJ, Gorgels A, Hancock EW, Josephson M, Kligfield P, Kors JA, Macfarlane P, Mason JW, Mirvis DM, Okin P, Pahlm O, van Herpen G, Wagner GS, Wellens H, American Heart Association Electrocardiography and Arrhythmias Committee, Council on Clinical Cardiology, American College of Cardiology Foundation, Heart Rhythm Society: AHA/ACCF/HRS recommendations for the standardization and interpretation of the electrocardiogram: part IV: the ST segment, T and U waves, and the QT interval: a scientific statement from the American Heart Association Electrocardiography and Arrhythmias Committee, Council on Clinical Cardiology; the American College of Cardiology Foundation; and the Heart Rhythm Society. Endorsed by the International Society for Computerized Electrocardiology. J. Am. Coll. Cardiol. 53, 982-991 (2009)

24. Sharieff GC, Rao SO: The pediatric ECG. Emerg. Med. Clin. North Am. 24, 195-208 (2006)

25. Sharma S, Whyte G, Elliott P, Padula M, Kaushal R, Mahon N, McKenna WJ: Electrocardiographic changes in 1000 highly trained junior elite athletes. Br. J. Sports Med. 33, 319-324 (1999)

26. Sheikh N, Papadakis M, Carre F, Kervio G, Panoulas VF, Ghani S, Zaidi A, Gati S, Rawlins J, Wilson MG, Sharma S: Cardiac adaptation to exercise in adolescent athletes of African ethnicity: an emergent elite athletic population. Br. J. Sports Med. 47, 585-592 (2013)

27. Sokolow M, Lyon T: The ventricular complex in left ventricular hypertrophy as obtained by unipolar precordial and limb leads. Am. Heart J. 37, 161-186 (1949)

28. Stolt A, Kujala UM, Karjalainen J, Viitasalo M: Electrocardiographic findings in female endurance athletes. Clin. J. Sport Med. 7, 85-89 (1997)

29. Tanguturi VK, Noseworthy PA, Newton-Cheh C, Baggish AL: The electrocardiographic early repolarization pattern in athletes: normal variant or sudden death risk factor? Sports Med. 42, 359-366 (2012)

30. Toufan M, Kazemi B, Akbarzadeh F, Ataei A, Khalili M: Assessment of electrocardiography, echocardiography, and heart rate variability in dynamic and static type athletes. Int. J. Gen. Med. 5, 655-660 (2012)

31. Walker J, Calkins H, Nazarian S: Evaluation of cardiac arrhythmia among athletes. Am. J. Med. 123, 1075-1081 (2010) 
32. Williams ES, Owens DS, Drezner JA, Prutkin JM: Electrocardiogram interpretation in the athlete. Herzschrittmacherther. Elektrophysiol. 23, 65-71 (2012)

33. Zaidi A, Ghani S, Sharma R, Oxborough D, Panoulas VF, Sheikh N, Gati S, Papadakis M, Sharma S: Physiological right ventricular adaptation in elite athletes of African and Afro-Caribbean origin. Circulation 127, 1783-1792 (2013)

34. Zdravkovic M, Perunicic J, Krotin M, Ristic M, Vukomanovic V, Soldatovic I, Zdravkovic D: Echocardiographic study of early left ventricular remodeling in highly trained preadolescent football players. J. Sci. Med. Sport 13, 602-606 (2010) 